\title{
Changes in fossil-fuel carbon emissions in response to interannual and interdecadal temperature variability
}

\author{
QIAN WeiHong", LU Bo \& LIANG HaoYuan \\ Monsoon and Environment Research Group, School of Physics, Peking University, Beijing 100871, China
}

Received September 16, 2010; accepted November 1, 2010

\begin{abstract}
Relationships on interannual and interdecadal timescales among global mean air temperature, $\mathrm{CO}_{2}$ concentrations and fossil-fuel carbon emissions in four major developed countries (the United States, the United Kingdom, France, and Germany) were analyzed. On an interannual timescale, the United States fossil-fuel carbon emissions tend to increase during cold winters and decrease during warm winters, which is opposite to the situation in summer. On an interdecadal timescale, cold (warm) periods both in the United States and globally agree with high (low) periods of fossil-fuel carbon emissions, with the temperature variability leading by 5-7 years. The leading correlation on the interdecadal timescale and the asymmetry in seasonal correlation on the interannual timescale indicate that temperature variability is a possible cause of changes in fossil-fuel carbon emissions.
\end{abstract}

global mean temperature, United States temperature, fossil-fuel carbon emissions, interannual, interdecadal, possible cause

Citation: Qian W H, Lu B, Liang H Y. Changes in fossil-fuel carbon emissions in response to interannual and interdecadal temperature variability. Chinese Sci Bull, 2011, 56: 319-324, doi: 10.1007/s11434-010-4279-9

The Third Assessment Report (TAR) of the Intergovernmental Panel on Climate Change (IPCC) [1] stated that "most of the observed warming over the last 50 years is likely to have been due to the increase in greenhouse gas concentrations". The IPCC Fourth Assessment Report (FAR) [2] further stated that "most of the observed increase in global average temperatures since the mid-20th century is very likely due to the observed increase in anthropogenic greenhouse gas concentrations." The IPCC FAR model experiments showed that warming of about $0.2^{\circ} \mathrm{C}$ per decade over the next two decades is projected for a range of emission scenarios. On the other hand, Knight et al. showed that the global mean temperature from 1999 to 2008 only increased by $0.07^{\circ} \mathrm{C}$, which is much lower than the warming trend of $0.18^{\circ} \mathrm{C}$ per decade during the period $1979-2008$ [3]. If the El Niño effect is removed, the warming trend during the last 10 years would be nearly zero. However, the annual carbon dioxide concentration growth rate was higher

*Corresponding author (email: qianwh@pku.edu.cn) during the latest 10 years than it was in the last 10 years of the 20th century. Thus, questions have been asked, such as "what happened to global warming?" [4] and "did global warming pause in the last decade?" [5].

As noted by the IPCC FAR, carbon dioxide $\left(\mathrm{CO}_{2}\right)$ is the most important anthropogenic greenhouse gas, and the primary cause of the increased atmospheric concentration of $\mathrm{CO}_{2}$ since the pre-industrial period has been the use of fossil fuels. It would be interesting to know the causality between fossil-fuel carbon emissions and temperature variability. To determine the cause-effect relationship, the global mean air temperature (HadCRUT3 [6]), atmospheric $\mathrm{CO}_{2}$ concentrations and fossil-fuel carbon emissions were studied and compared on interannual and interdecadal timescales in this paper. Annual and monthly United States temperature datasets were downloaded from http://www.ncdc.noaa.gov/oa/ climate/research/cag3/na.html and http://www1.ncdc.noaa. gov/pub/data/cirs/, respectively. Fossil-fuel carbon emissions datasets were downloaded from the Carbon Dioxide Information Analysis Center (CDIAC) for annual periods 
(1850-2006) in the cases of four major developed countries (the United States, the United Kingdom, France, and Germany) and monthly periods (1981-2003) in the case of the United States alone [7]. The historical annual atmospheric $\mathrm{CO}_{2}$ concentration dataset (1850-1978) was obtained from analyses of three ice cores [8]. Keeling began in situ measurement of the $\mathrm{CO}_{2}$ concentration in 1958 [9]. For the overlap of 21 years (1958-1978), the two datasets are comparable, and a combined $\mathrm{CO}_{2}$ concentration series for 18502006 was thus derived to examine the trends of fossil-fuel carbon emissions on an interdecadal timescale.

Turning points were determined from the two time series. For each series with length of 157 years, the sliding 5-year trends were calculated, and then the turning points were determined employing a scanning $t$ test [10] of the sliding trend series over 10-20-year timescales. This method is referred to as the slope-t-test.

Empirical mode decomposition [11] and singular spectrum analysis [12] have been widely applied to time series to obtain various components including long-term tendencies. However, physical mechanisms cannot be explained by the resulting components, particularly the first two components. To separate the interannual and interdecadal signals, simple linear detrending was applied to both series in this paper.

\section{United States fossil-fuel carbon emissions and temperature}

During the 20th century, the United States was the world's largest emitter of fossil-fuel carbon. The United States fossilfuel carbon emissions have a long-term trend and interannual and interdecadal variability. To clarify the interannual relationship between fossil-fuel carbon emissions and temperature in the United States, monthly datasets (19812003) provided by CDIAC were used. Here we mainly focus on summer and winter seasons.

During the period 1981-2002, the winter fossil-fuel carbon emissions in the United States increased by 45 million tons per decade. The winter temperature in the United States also increased by about $0.78^{\circ} \mathrm{C}$ per decade. After removing their long-term trends, the interannual winter temperature and interannual winter carbon emissions are shown in Figure 1(a). Their correlation coefficient is -0.58 at the $99 \%$ confidence level. The carbon emissions peaked in 1981 and 2000, at which time the winters were cold. There were relatively warm winters in 1982, 1986, 1991, 1994, 1997-1998 and 2001, at which time the United States carbon emissions were low. There are two explanations for this phenomenon. The first explanation is that the United States winter temperature affects the fossil-fuel carbon emissions. A cold winter means that extra fossil fuel is burned for warmth. The second explanation is that the United States fossil-fuel carbon emissions affect the United States winter tempera- ture. The greater fossil-fuel carbon emissions release more aerosols, which scatter solar radiation and reduce temperatures.

Similarly, the relationship between summer temperature and summer fossil-fuel carbon emissions in the United States is also analyzed. After removing long-term trends (18 million tons per decade and $0.28^{\circ} \mathrm{C}$ per decade, respectively), the interannual summer temperature and interannual summer carbon emissions are shown in Figure 1b. In contrast to winter, they have significant positive correlation. The correlation coefficient is +0.56 at the $99 \%$ confidence level. This can be explained by the burning of fossil fuel to generate electricity for cooling purposes in summer. The cooling effects of aerosols do not make sense in this case. The amplitudes of temperature and emission variations are larger in winter, about 2-3 times those in summer. Thus, the annual relationship between temperature and emissions was determined by winter.

To reach a more reliable conclusion, longer datasets (1900-2006) were used. The annual temperature and annual fossil-fuel carbon emissions in the United States have linear long-term trends $\left(0.68^{\circ} \mathrm{C}\right.$ per century and 1.37 billion tons per century, respectively) as shown in Figures 2(a) and (b). We then take the 9-year running average of the trend-removed series (Figure 2(c)). The coefficient of correlation between the two 9-year running average series peaks at -0.45 (99\% confidence level) when the United States annual temperature leads carbon emissions by 7 years. However, the correlation coefficient is only -0.05 when the United States annual carbon emissions lead the temperature by 7 years. After removing the 9-year running average, the interannual variability can be observed (Figure 2(d)). The correlation coefficient peaks at -0.36 when they are synchronous. If the United States temperature leads carbon emissions by 1 or 2 years, the correlation coefficient is -0.23 (99\% confidence level) or 0.15 . If carbon emissions lead the United States temperature by 1 year, the correlation coefficient is 0.03 . These results indicate that the cold-warm variations lead the fossil-fuel carbon emissions in the United States winter on the interannual timescale.

\section{Fossil-fuel carbon emissions in four major developed countries and global temperature}

On the interdecadal timescale, similar variability was noted for the Northern Hemisphere and the global mean temperature series in the last century. From 1850 to 2008, the long-term trend of the global mean temperature was about $0.44^{\circ} \mathrm{C}$ per century [13]. Figure 3 shows fossil-fuel carbon emissions in four major developed countries (the United States, the United Kingdom, France, and Germany). Since industrialization, the total emissions of the four countries have had an increasing trend similar to that of the United States. However, the global mean temperature had an about 

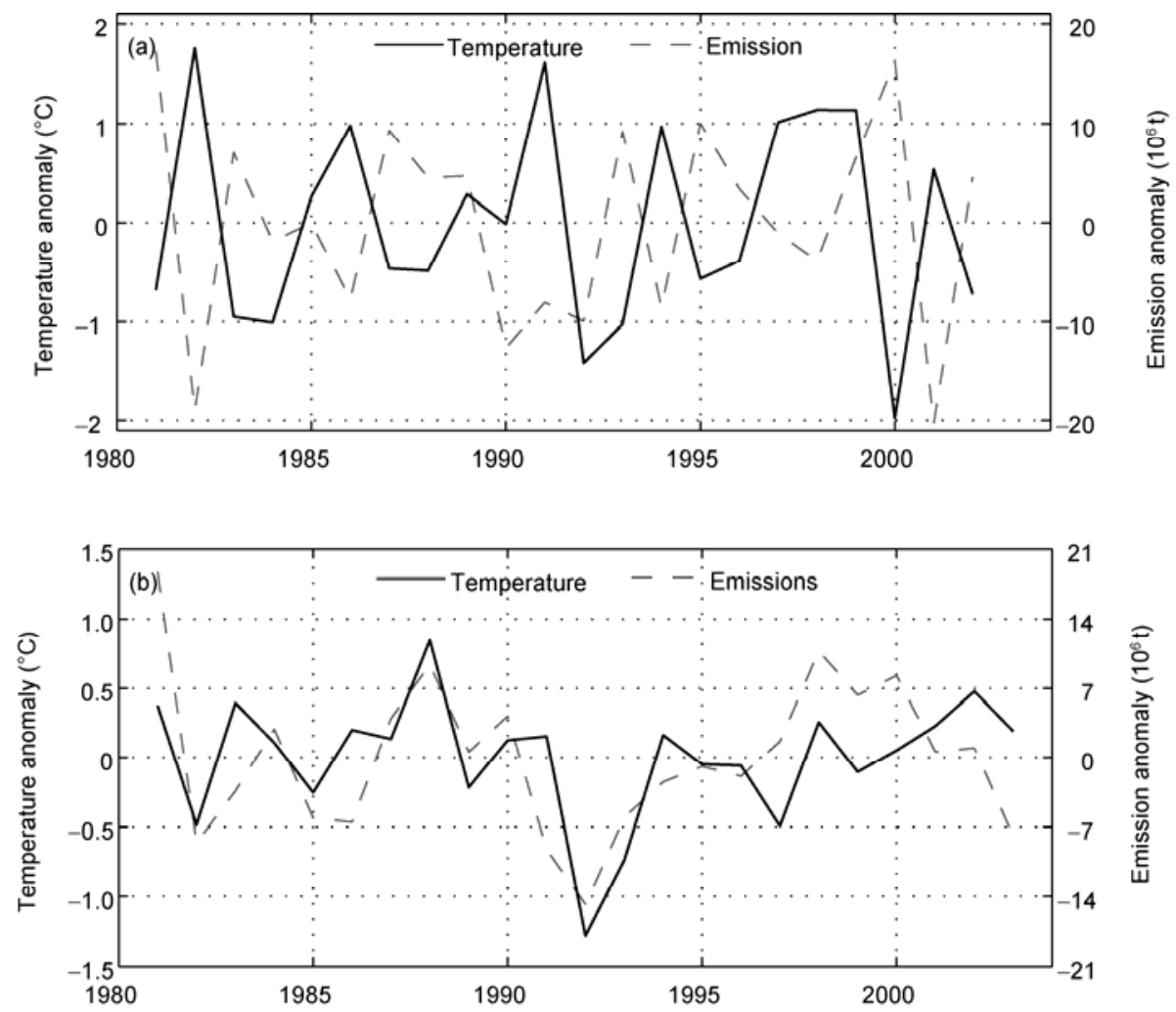

Figure 1 Trend-removed seasonal mean temperature anomalies (solid line) and trend-removed total three-month fossil-fuel carbon emissions anomalies (dashed line) from 1981 to 2002 (2003) in the United States. (a) In winter (DJF) and (b) summer (JJA).

$0.5^{\circ} \mathrm{C}$ variability on interdecadal and century scales before industrialization [14]. Limited by the length of data, we only focused on their relationship on the interdecadal timescale.

From 1850 to 1918 , fossil-fuel carbon emissions in the four countries together increased to a first peak in the $1910 \mathrm{~s}$, but the global mean temperature entered the first relatively cold period in the beginning of the 20th century. Around the 1930s, the increasing trend of fossil-fuel carbon emissions slowed, but the global mean temperature entered a relatively warm period in the 1940s. Around the 1970s, emissions increased rapidly, but the global mean temperature did not increase. Carbon emissions in Japan and Canada also peaked in the 1970s (data not shown) [15]. For the period of 1980-2006, the carbon emissions slowed again and corresponded to the warmest global mean temperature since the beginning of the 20th century.

It is noticeable from Figure 3 that carbon emissions increased linearly from 1850 to 1899 in response to industrialization, although the interdecadal variability of the global mean temperature was pronounced. This implies that the carbon emissions in the 19th century did not depend upon the global mean temperature or requirements for human comfort (e.g. cooling and heating of living spaces) and was only driven by industrialization. Since the beginning of the 20th century, the long-term trend of the carbon emissions continues to be driven by industrial development. However, variations in the carbon emissions were caused by temperature oscillations that affected human activity.

Fossil-fuel carbon emissions in the four countries and global mean temperature since 1900 were considered in this study. Figure 4 shows their interdecadal relationship after long-term trends were removed. On this timescale, there were high (low) emissions in cold (warm) years. The correlation coefficient peaks at -0.48 (99\% confidence level) when the annual temperature leads carbon emissions by 5 years. If carbon emissions lead the annual temperature by 5 years, the correlation coefficient is -0.32 . After calculating the 9-year running average, the correlation coefficient peaks at -0.68 ( $99 \%$ confidence level) when the annual temperature leads carbon emissions by 6 years. If carbon emissions lead the annual temperature by 6 years, the correlation coefficient is -0.35 . This leading phase indicates that global mean temperature variations could affect the total fossil-fuel carbon emissions of the four countries on the interdecadal timescale.

\section{Human-induced changes in atmospheric $\mathrm{CO}_{2}$ concentrations}

Marland et al. [16] pointed out that the rates of global fossil-fuel $\mathrm{CO}_{2}$ emissions can be divided into four periods1850-1907, 1907-1949, 1949-1972, and 1972-2005-with 


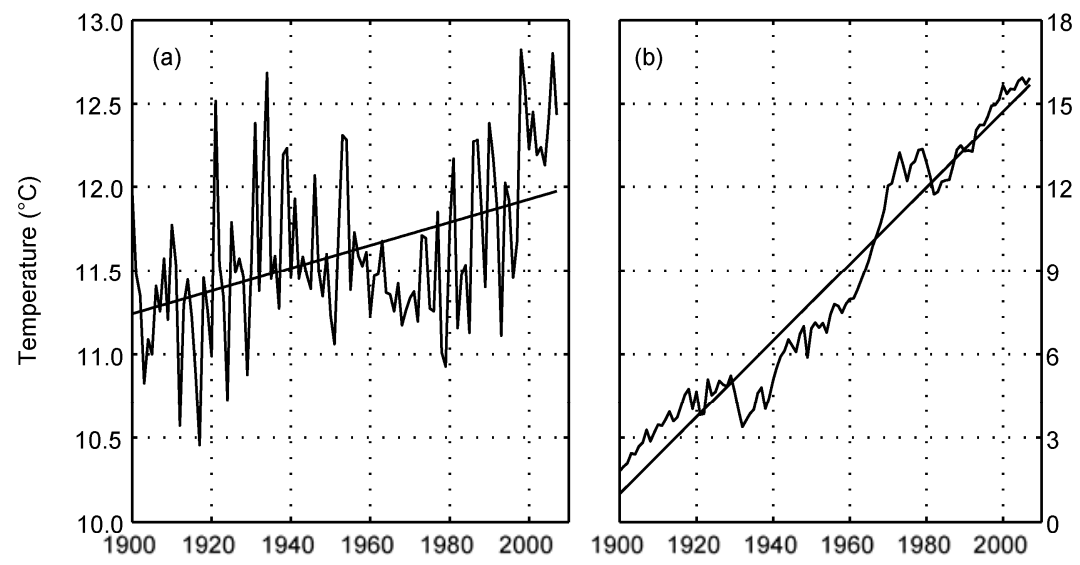

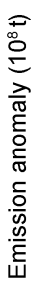
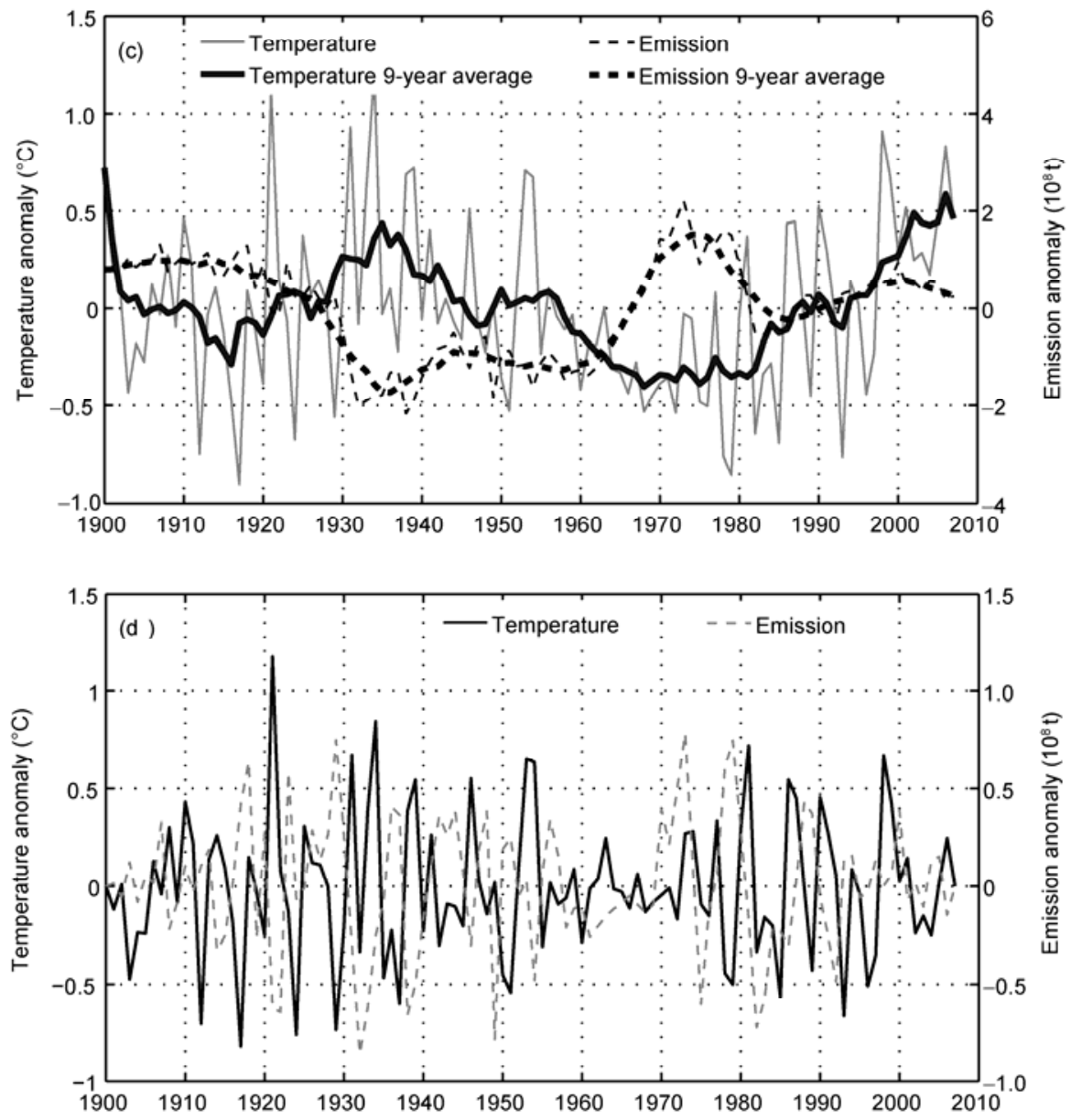

Figure 2 Time series of the annual temperature and fossil-fuel carbon emissions in the United States. (a) Annual temperature anomaly (curve) and its linear trend (straight line); (b) annual fossil-fuel carbon emissions (curve) and its linear trend (straight line); (c) trend-removed temperature anomaly (thin solid line) and its 9-year running average (thick solid line), trend-removed fossil-fuel carbon emissions (thin dashed line) and its 9-year running average (thick dashed line); (d) annual temperature variability (solid line) and annual fossil-fuel carbon emissions variability (dashed line).

the increasing rates of $4.4 \%, 1.3 \%, 4.3 \%$ and $1.2 \%$, respectively. The first period was dominated by coal burning, and thus, $\mathrm{CO}_{2}$ emission increased rapidly. During the second period, the use of oil and natural gas reduced the rate of increase by $70 \%$. In the third period, the massive use of oil and natural gas meant that the rate of increase was on a par with that of the first period. During the last period, the rate of increase declined again, possibly owing to the use of nuclear energy.

Using the slope-t-test, the turning points of total emissions in the four developed countries, atmospheric $\mathrm{CO}_{2}$ concentration and global mean temperature series were determined. 


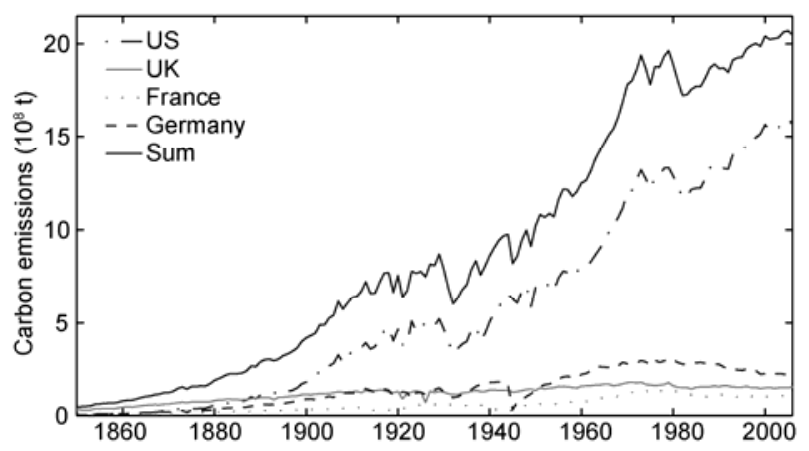

Figure 3 Annual fossil-fuel carbon emissions of four major developed countries (the United States (US), the United Kingdom (UK), France, and Germany) and their sum for the period 1850-2006.

Before 1912, the total emissions in the four countries increased by $9.3 \times 10^{6}$ tons per year. During 1912-1947, the rate of increase in the total emissions declined to $6.2 \times 10^{6}$ tons per year. The rate of increase increased to $35.0 \times 10^{6}$ tons per year during 1947-1972 and declined to $6.6 \times 10^{6}$ tons per year during 1972-2005. The emissions in the United Kingdom, Germany and France declined during the two world wars. In addition, the increasing and declining periods of emissions in the four countries agree with the variations in total global emission.

Since industrialization, the atmospheric $\mathrm{CO}_{2}$ concentration has increased at different rates during different periods. During the period of $1850-1900$, the atmospheric $\mathrm{CO}_{2}$ concentration increased by 2.9 parts per million by volume (ppmv) per decade, and the rate of increase was $3.2 \mathrm{ppmv}$ per decade during the period 1900-1952. The rate of increase was 8.4 ppmv per decade during 1952-1976 and 15.8 ppmv per decade during 1976-2005. These four periods of increasing atmospheric $\mathrm{CO}_{2}$ concentration reflect the accumulation of fossil-fuel carbon emissions (Table 1). Oscillations in global mean temperature had phases opposite to those of fossil-fuel carbon emissions on an interdecadal timescale.
The Keeling curve is a graph showing a steady increase in the mean atmospheric $\mathrm{CO}_{2}$ concentration since 1958 [9]. This increase in atmospheric $\mathrm{CO}_{2}$ concentration is considered to be largely due to the combustion of fossil fuels, and has been accelerating in recent years. In the last 10 years (2000-2009), the atmospheric $\mathrm{CO}_{2}$ concentration increased $2.04 \mathrm{ppmv}$ per year, compared with a rate of increase of about 1.46 ppmv per year over the last 50 years. The rapid increase of the atmospheric $\mathrm{CO}_{2}$ concentration over the last decade was inconsistent with the global mean temperature in the same period.

\section{Conclusion and discussion}

The relationships among fossil-fuel carbon emissions, global mean temperature and atmospheric $\mathrm{CO}_{2}$ concentrations were analyzed in this paper on interannual and interdecadal timescales.

(1) The increase of the atmospheric $\mathrm{CO}_{2}$ concentration is an accumulation of fossil-fuel carbon emissions. During the last 150 years, there were four distinct periods of the increasing rate of fossil-fuel carbon emissions, characterized by a "high-low-high-low" oscillation, leading to different increasing rates of the atmospheric $\mathrm{CO}_{2}$ concentration in each period. The long-term increasing trend of fossil-fuel carbon emissions illustrates the acceleration of industrialization. The oscillations of carbon emissions were affected by temperature fluctuations on interannual and interdecadal timescales. Because of data length limitations, the cause of the long-term trend on the century scale was not discussed in this paper.

(2) On an interannual time scale, the temperature affects the level of fossil-fuel carbon emission. During the winter, a $1.5^{\circ} \mathrm{C}$ warmer temperature reduces emissions by $10-20$ million tons and a $2^{\circ} \mathrm{C}$ colder temperature increases emissions by 16.4 million tons in the United States. On the contrary, the fossil-fuel carbon emissions and air temperature have

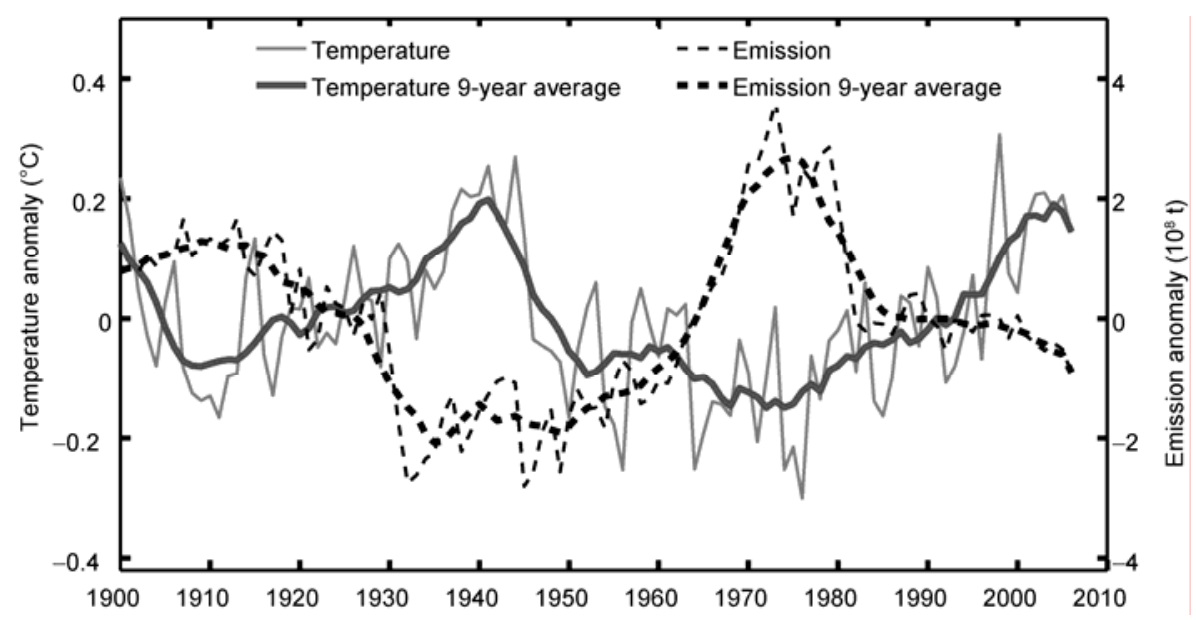

Figure 4 Trend-removed global mean temperature anomaly (thin solid line) and its 9-year running average (thick solid line), trend-removed fossil-fuel carbon emissions in four major developed countries (thin dashed line) and its 9-year running average (thick dashed line). 
Table 1 Comparison among global fossil-fuel $\mathrm{CO}_{2}$ emissions [16], total carbon emissions of four major developed countries, rate of increase in the atmospheric $\mathrm{CO}_{2}$ concentration and global warming rate based on the "slope-t-test"

\begin{tabular}{|c|c|c|c|c|c|}
\hline \multicolumn{2}{|l|}{ Period } & 1 & 2 & 3 & 4 \\
\hline \multirow{2}{*}{$\begin{array}{l}\text { Global emission } \\
\text { increasing rate }\end{array}$} & Years & $1850-1907$ & $1907-1949$ & 1949-1972 & $1972-2005$ \\
\hline & Rates & $4.4 \%$ (high) & $1.3 \%$ (low) & $4.3 \%$ (high) & $1.2 \%$ (low) \\
\hline \multirow{2}{*}{ Emissions of four countries } & Years & $1850-1912$ & $1912-1947$ & $1947-1972$ & $1972-2005$ \\
\hline & $10^{6} \mathrm{tC} / \mathrm{a}$ & 9.3 (high) & 6.2 (low) & 35.0 (high) & 6.6 (low) \\
\hline \multirow{2}{*}{ Atmospheric $\mathrm{CO}_{2}$ concentration } & Years & $1850-1900$ & $1900-1952$ & $1952-1976$ & 1976-2005 \\
\hline & $\mathrm{ppmv/10 \textrm {a }}$ & 2.9 & 3.2 & 8.4 & 15.8 \\
\hline \multirow{2}{*}{ Global warming } & Years & $1878-1911$ & 1911-1944 & $1944-1976$ & $1976-1998$ \\
\hline & ${ }^{\circ} \mathrm{C} / 10 \mathrm{a}$ & -0.088 & 0.160 & 0.003 & 0.175 \\
\hline
\end{tabular}

significant positive correlation in summer. During 19121954 and 1973-2000, the United States annual temperature had large interannual variability, as did fossil-fuel carbon emissions. There are significant negative correlations when the United States annual temperature leads carbon emissions by $0-1$ years on an interannual timescale.

(3) On an interdecadal timescale, total fossil-fuel carbon emissions in four developed countries were high (low) during the relatively cool (warm) periods. The temperature change leads carbon emissions by about 5 years, which may indicate that human activities have a lag time in response to the climate changes. Therefore, temperature variability could be a cause of changes in fossil-fuel carbon emissions on the interdecadal timescale.

We would like to thank Prof. Wang S. W. for his suggestion of including seasonal and interannual analysis in this paper. Thanks are due also to Dr. Deng Y. for his suggestion of adding the study of the United States temperature and the United States seasonal emission. We appreciate meaningful suggestions made by the reviewers and guest editor.

1 IPCC (TAR). Summary for Policymakers. In: Climate Change 2001: The Physical Science Basis. In: Houghton J T, Ding Y, Griggs D J, et al, eds. Contribution of Working Group I to the Third Assessment Report of the Intergovernmental Panel on Climate Change. Cambridge, United Kingdom and New York: Cambridge University Press, 2001

2 IPCC (FAR). Summary for Policymakers. In: Climate Change 2007: The Physical Science Basis. In: Solomon S D, Qin D, Manning M, et al, eds. Contribution of Working Group I to the Fourth Assessment Report of the Intergovernmental Panel on Climate Change. Cambridge, United Kingdom and New York: Cambridge University Press, 2007
3 Knight J, Kennedy J J, Folland C, et al. Do global temperature trends over the last decade falsify climate predictions? Bull Amer Meteor Soc, 2009, 90: S22-S23

4 Kerr R A. What happened to global warming? scientists say just wait a bit. Science, 2009, 326: 28-29

5 Wang S W, Luo Y, Tang G L, et al. Does the global warming pause in the last decade? (in Chinese). Adv Clim Change Res, 2010, 6: 95-99

6 Brohan P, Kennedy J J, Harris I, et al. Uncertainty estimates in regional and global observed temperature changes: A new dataset from 1850. J Geophys Res, 2006, 111: D12106, doi:10.1029/2005JD006548

7 Carbon Dioxide Information Analysis Center (CDIAC). Global, regional, and national fossil fuel $\mathrm{CO}_{2}$ emissions. http://cdiac.ornl.gov

8 Etheridge D M, Steele L P, Langenfelds R L, et al. Natural and anthropogenic changes in atmospheric $\mathrm{CO}_{2}$ over the last 1000 years from air in Antarctic ice and firn. J Geophys Res, 1996, 101: 4115-4128

9 Keeling C D, Bacastow R B, Bainbridge A E, et al. Atmospheric carbon dioxide variations at Mauna Loa Observatory, Hawaii. Tellus, 1976, 28: 538-551 (www.esrl.noaa.gov/gmd/ccgg/trends/)

10 Jiang J M, Fraedrich K, Zou Y R. A scanning $t$ test of multiscale abrupt changes and its coherence analysis (in Chinese). Chin J Geophys, 2001, 44: 32-40

11 Wu Z H, Huang $\mathrm{N}$ E, Long S R, et al. On the trend, detrending, and variability of nonlinear and nonstationary time series. Proc Natl Acad Sci USA, 2007, 104: 14889-14894

12 Schlesinger M E, Ramankutty N. An oscillation in the global climate system of period 65-70 years. Nature, 1994, 367: 723-726

13 Qian W H, Lu B, Zhu C W. How would global-mean temperature change in the 21st century? Chinese Sci Bull, 2010, 55: 1963-1967

14 Qian W H, Lu B. Periodic oscillations in millennial global-mean temperature and their causes. Chinese Sci Bull, 2010, 55: 4052-4059

15 Ding Z L, Duan X N, Ge Q S, et al. Control of atmospheric $\mathrm{CO}_{2}$ concentration by 2050: An allocation on the emission rights of different countries. Sci China Ser D-Earth Sci, 2009, doi: 10.1007/s11430009-0155-3

16 Marland G, Boden T A, Andres R J. Global, regional, and national $\mathrm{CO}_{2}$ emissions. In trends: A compendium of data on global change. 2007, Carbon Dioxide Information Analysis Center, Oak Ridge National Laboratory, U.S. Department of Energy, Oak Ridge, Tennessee, U.S.A

Open Access This article is distributed under the terms of the Creative Commons Attribution License which permits any use, distribution, and reproduction in any medium, provided the original author(s) and source are credited. 